\title{
Sustainable engineering challenges towards Industry 4.0: A comprehensive review
}

\author{
Amina Krdžalić ${ }^{*}$, Lejla Hodžić ${ }^{2}$ \\ ${ }^{1}$ Technical University Graz, Austria \\ ${ }^{2}$ International University of Sarajevo, Bosnia
}

\begin{abstract}
*Corresponding author: amina.krdzi@gmail.com "(C) The Author 2019.

Published by ARDA.

Abstract

This article reviews Industry 4.0, its emerging phase, implementation, challenges, benefits, etc. It combines various fields where it has any influence and leaves some changes and where it requires some adaptation. Papers from the last 4 years are taken and analyzed, what is written about this topic in various countries with different backgrounds and economic development. Industry 4.0 affects the production environment by introducing new technologies which require a bettereducated workforce so it affects education and requires some changes in curricula and way of teaching. It brings new challenges and asks for a new approach from management to be able to handle fast and big changes in the business environment and to implement such innovation in production effectively.
\end{abstract}

Keywords: Industry 4.0, Manufacturing, Education and qualification, Internet of Things

\section{Introduction}

Industry 4.0 (the 'fourth industrial revolution') refers to the current trend of improved automation, machineto-machine and human-to-machine communication, artificial intelligence, continued technological improvements and digitalisation in manufacturing. This trend is enabled by four key drivers: rising data volumes, computational power and connectivity; the emergence of analytics and business-intelligence capabilities; new forms of human-machine interaction, such as touch interfaces and augmented-reality systems and; improvements in transferring digital instructions to the physical world, such as robotics and 3D printing. Industry 4.0 is now a globally accepted reality that is affecting almost every industry across the world and is rapidly transforming how businesses operate [1].

Each paradigm affect different fields and there are always challenges in implementing new way of doing, especialy when paradigm is happening fast and there is no enough time to process everything on time. Many lacks arise and new procedures are going to be undertaken. The following paper explains particulary Industry 4.0 is, what it brings and how it affects various fields. It will be discussed what are main challenges to be overcome, what are possible solutions and ways of doing it and what are the benefits of implementing Industry 4.0 in every production and related sides.

The data on this matter is collected from Scopus and the results were represented graphically and numerically. More than three thousand of papers are published on internet through various web-pages in past 6 years, from

This work is licensed under a Creative Commons Attribution License (https://creativecommons.org/licenses/by/4.0/ ) that allows others to share and adapt the material for any purpose (even commercially), in any medium with an acknowledgement of the work's authorship and initial publication in this journal. 
the time when it started to be talked about this topic.

Since Industry 4.0 comes from Germany, in the Figure 1 is shown that such topic is the most present in that country, which is not surprising. About of $35 \%$ of research papers on this topic is written by German scientists from German universities/institutes and presented at conferences in Germany. That percentage is witnessing that automation is the best developed and currently in use in Germany. This topic becomes hot as well in China, Italy, US, UK, Austria and Spain with more than 3\% of all papers written on this topic. On the following graph, only countries with more than 20 published papers are presented. Bosnia and Herzegovina, as expected, is not on the graph since only one paper on this topic is published. Similar story is related to neighboring countries from Western Balkans, since none of those countries are on the graph.

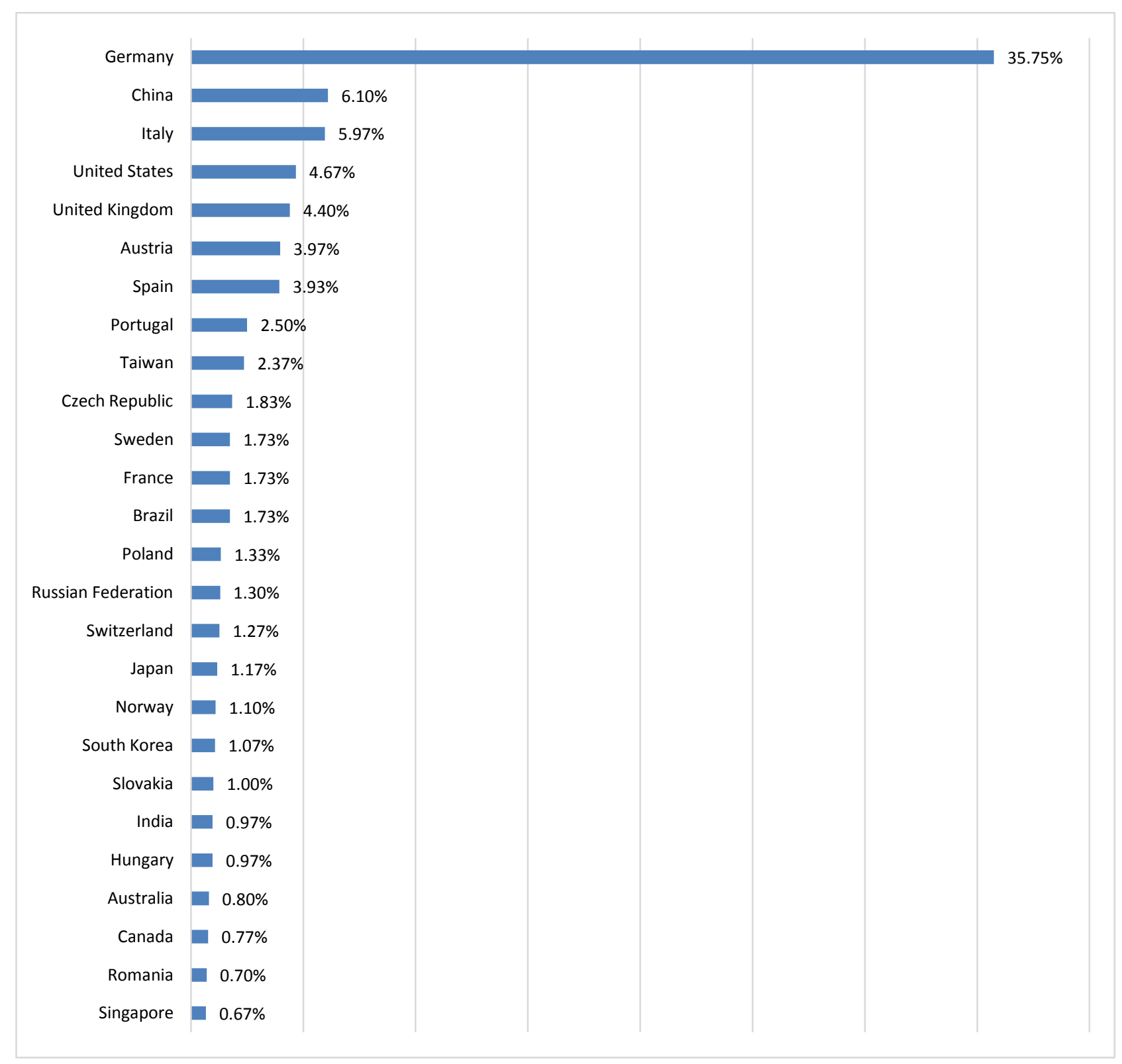

Figure 1. Publications per country

Since this topic is very innovative and hot today, all countries are approaching to implement such model and concept to its manufacturing and production processes. Technology is developing new things every day which can facilitate many processes. Since Industry 4.0 is actually automation of industry, following graph is presenting which fields are dealing the most with this topic. 
It was expected to have Engineering, Computer Science, Business, Management, Accounting and Decision Science among $80 \%$ of all papers published since Industry 4.0 is about automation in manufacturing which help to make better decision, increase productivity and decrease various costs. However, still various fields of study find something for themselves that is applicable and can help them to differentiate on a market, to find better solutions and to constantly approach to perfection and development.

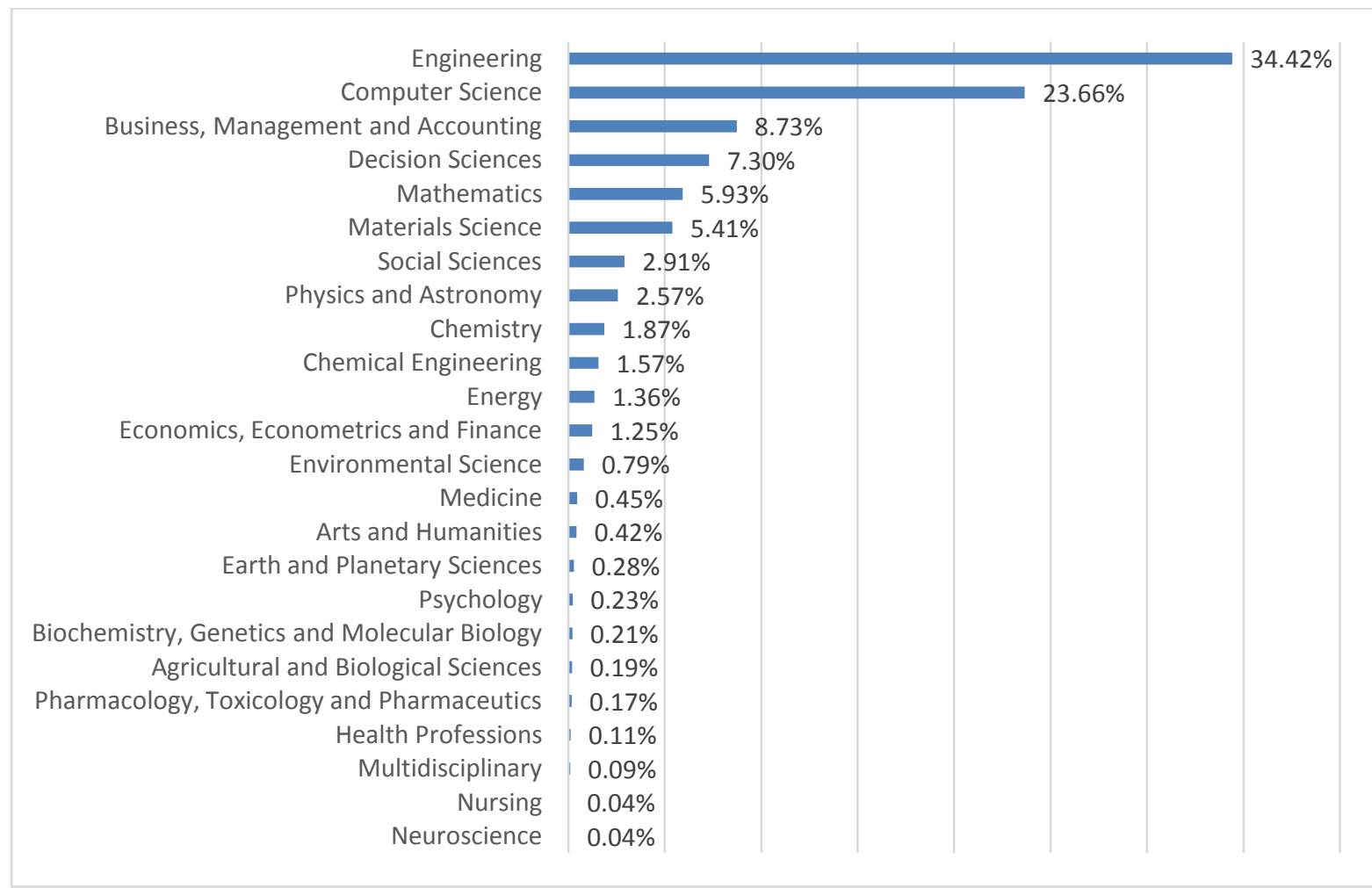

Figure 2. Publications per subject area

The first mention of this topic was in 2011, in 2012. The idea has been developing and in 2013 it was officially presented. From Figure 3 it can be seen that number of published paper on this topic is exponentially increasing over the years, and the first papers were written in 2012 when idea was in development phase.

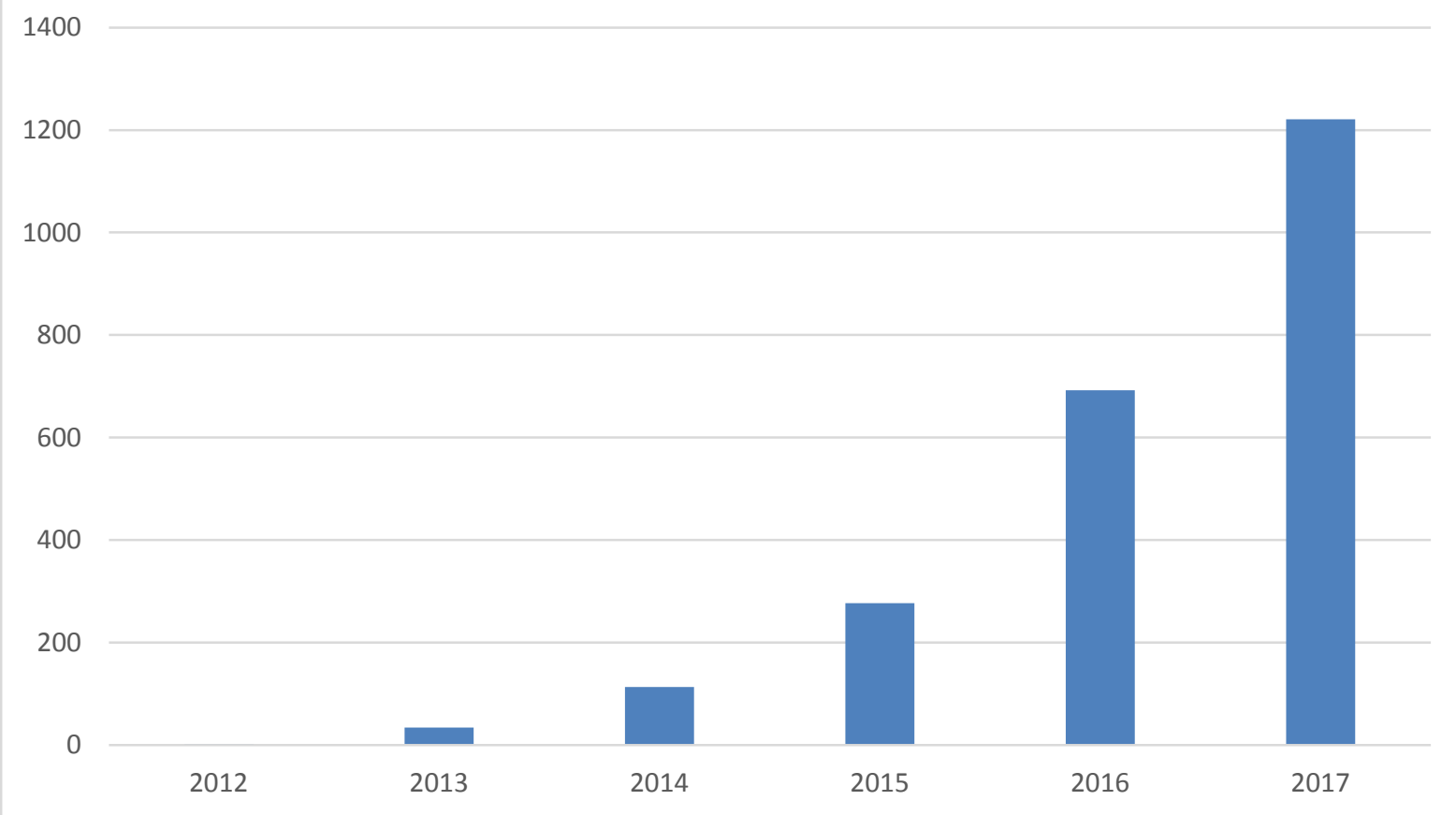

Figure 3. Publications per years 
Table 1. shows the structure of the paper and briefly summarized which topics have been tackled and researched already.

Table 1. Industry 4.0 topic categories discussed in the research papers

\begin{tabular}{lll}
\hline Title & Topics/key words & References \\
\hline Technology & Cyber Physical System (CPS) & {$[2][3][4][5][6]$} \\
& Internet of Things (IoT) & {$[7][8][9][10]$} \\
& Internet of Services & {$[11][12][13][14]$} \\
& Big Data & {$[15][16][17][18]$} \\
& Artificial Intelligence & {$[19][20][21][22]$} \\
& Cloud Computing & {$[23][24][25][26]$} \\
& Robotics & {$[27][28][29]$} \\
& Machine Learning & \\
& Digitalization & \\
& Automation & \\
& Network and System Communication & \\
\hline Education and qualification of people & Curricula & {$[30][31][32][33]$} \\
& Laboratories & {$[34][33][30][35]$} \\
& Libraries & {$[36][37]$}
\end{tabular}

\begin{tabular}{|c|c|c|}
\hline \multirow[t]{10}{*}{ Manufacturing/Production } & Quality improvement & {$[38] \quad[39] \quad[39]$} \\
\hline & Smart products & {$[40][41][41][42]$} \\
\hline & Lean production & {$[43][44][45][46]$} \\
\hline & Ergonomics & [47] [48] [49] [50] \\
\hline & Process planning (scheduling, sequencing) & {$[51][52][53][54]$} \\
\hline & Mass customization & {$[55][56][57][58]$} \\
\hline & Additive Manufacturing & {$[59][60][61][62]$} \\
\hline & Flexibility & {$[63]$} \\
\hline & Assembly Systems & [64] [65] [66] [67] \\
\hline & Computer Integrated Manufacturing (CIM) & {$[68]$} \\
\hline \multirow[t]{7}{*}{ Management/Business } & Risk Management & [69] [70] [71][72] \\
\hline & Supply Chain Management & {$[72][73][74][75]$} \\
\hline & Business Model & {$[30][51][76]$} \\
\hline & Sustainability & \\
\hline & Maintenance panning & \\
\hline & Data Management & \\
\hline & Logistics 4.0 & \\
\hline \multirow[t]{6}{*}{ Challenges } & Social & [77] [76] [78] [79] \\
\hline & Risks & [80] [81] [82] [83] \\
\hline & Manufacturing & [84] [85] [86] [87] \\
\hline & Technology & [88] [89] [90] [26] \\
\hline & Standardization & [45] [52] \\
\hline & Environment & \\
\hline
\end{tabular}




\section{Technologies in the Industry 4.0}

\subsection{Digitalization}

Industry 4.0 is more and more-less of a visionary and more of a realistic concept. Along with the upcoming technologies, it is also concerned about the value-added activities and reducing or overall avoiding wastes. It's nine pillars include: big data and analytics, autonomous robots, simulation, System Integration: Horizontal and Vertical System Integration, The Industrial Internet of Things, Cyber security and Cyber Physical Systems (CPS), the cloud computing, Additive Manufacturing and Augmented Reality [2].

The main initiator of innovation and change in economy and industry is digitization. Digitization can be defined as the continuous convergence of the real and the virtual world. Both the economy and the industry are transformed by the amount of data and the uprising of technology, which characterize the modern era. The main technologies of Industry 4.0, such as Internet of Things and Data and Services, have an important role in energy transformation, health care, securing competitive position and in mobility and logistics sector [3].

Industrial leaders are introducing innovative, data-based services in the operations processes. We are witnessing a huge increase in digitalization, which is a phenomenon behind the "industrial internet" and "digital factory" [4]. In Industry 4.0, human labor works along with the smart devices and machine, and this relationship is known as human-machine collaboration. Furthermore, people should interact and exchange information with the mentioned smart devices, which is known as human-machine collaboration. Field of cognitive computing has a goal of reproducing human skills through artificial models and algorithms onto the machines in order to make them capable of handling human problems and tasks, and at the same time be able to make decisions [5].

\subsection{Network and system communication}

Information and Communication Technologies support most of the industrial production processes. The IT revolution made many transformations in organizations, by the processes of mechanization and the electricity brought by the previous industrial revolutions [6]. To minimize human effort in the manufacturing process and to make the whole manufacturing process more independent all the tools need to be well connected and to allow sensory input and actuator output of some kind. This became more and more possible with the emergence of IoT and new communication technologies. With the promise of everyday Internet-enabled devices as end points, it is possible to access industrial data on a large scale and with better accuracy as well as to allow dynamic automation of manufacturing processes. All this is only possible with secure and reliable communication, which is coming in new technologies such as Ethernet time-sensitive networking (TSN), fifth-generation $(5 \mathrm{G})$ telecom networks [7].

\subsection{Internet of things and big data}

With the invention of the internet, what primarily led to Industry 4.0 is the Internet of Things. Today's number of digital devices is estimated in billions. The Internet of Things is a term referring to connecting all of these devices to the Internet. This way, IoT will reach all industries and reshape the traditional manufacturing, where the special prerequisite is the communication [8]. Machines would stream data through wireless network and send this data to smart product provider's centers, to be analyzed. The exchange of information is only between machines. IoT technology makes possible the creation of new products and business models that promise gains in all industries, and today this effect can be largely seen in automotive industry. The period of the fourth industrial revolution is specifically characterized by automation, digitization and increased use of electronics and information technologies in manufacturing [9].

Beside the Internet of Things, Industry 4.0 is tackling another interesting term, the Internet of Anything (IoA). IoA is planned to be composed of different industries and will allow them to share data securely over the Internet, for gaining economical and production benefits [10]. Recent advancements in industrial IoT, 
Industrial wireless networks, big data, cloud computing allowed introduction of fourth industrial revolution. Based on software advancements in these areas, there is a need for software defined industrial IoT to make the network more flexible. This software defined architecture must encompass protocols that will allow cyberphysical systems to communicate coherently and utilize information from heterogeneous and sensory enabled devices. Software defined IIoT architecture will allow further advancements in Industry 4.0 [11]. Furthermore, with the growth of Industry 4.0, high volumes of data are emerging, which can be used in the analysis of the social and communication networks [12].

\subsection{Cyber-physical systems (CPS)}

Materials 1.0 were the ones seen in Iron Age Stone Age and Bronze Age. Materials 2.0 is characterized with mass production lines along with electrical energy. With the Materials 3.0 witnessed modernization of the production lines enabled by the sudden upraise of the Information technologies and digitalization, where the "Materials 3.0" is computational materials science. Industry 4.0 is the production and manufacturing enabled by the cyber-physical systems. Materials 4.0 is expected to make new kinds of tools for the industry that include cheaper sensors, cameras, wireless communication and different kinds of embedded systems [13]. Equipment automation is one of the main contributors for launching the Fourth Industrial Revolution [14].

The recently emerged methodologies for interconnected systems such as cyber-physical systems are focused to closely monitor the information and synchronize it between the physical connected systems and cyber computational space. The methodology behind the CPS (Cyber-Physical Systems) relies on monitoring the information and synchronizing it between the physical systems and components with cyber computational space. Today's advancement in this field works toward the integration of CPS in manufacturing [15]. Recent advances in Information and Communications Technologies (ICT) could give also to manufacturing industries the competences required to develop novel sustainable products embedded with a dedicated infrastructure able to provide more service functionalities to customer. In this context, the application of Internet of Things (IoT) have allowed developing the so named Product Service Systems (PSSs). For example, the application of ICT technologies and specifically the adoption of IoT at a plant of plastic extrusion pipes have allowed optimizing the production process in terms of energy efficiency. PSS implies the design of a wide set of services that should be delivered by the physical product through the implementation of a dedicated hardware and software infrastructure. This allows delivering to customers new personalized service functionalities able to satisfy their needs and expectations which lead to reduction of cost for additional sensors and cloud technologies, enabling data monitoring, storage and post-elaboration [16]. ICPSs are expected to empower the transformation of industry and business at large to a digital, adaptive, networked, and knowledge-based industry with significant long-term impact on the economy, society, environment, and citizens. The Cyber Physical Systems application in industrial settings is expected to revolutionize the way companies perform their business in wide range of uses and interactions, from shop-floor to business interactions, from suppliers to customers, and from design to support across the whole product and service lifecycle. Therefore, the CPS are one of the main features of Industry 4.0, and have a huge impact on how the transformation of industry will take place. This transformation is characterized with digital, adaptive, networked and knowledge-based industry with long-term impact on economy, business and overall environment [17].

Along with the Cyber-Physical Systems (CPS), there is Cyber-Human Systems (CHS), as one of the main markers of Industry 4.0. Cyber-Human Systems allow workers to perform their tasks more efficiently and safely, along with increased control and quality monitoring of manual manufacturing jobs. Future smart manufacturing system relies on both Cyber-Physical and Cyber-Human Systems [18]. With the advent of Industry 4.0 and all the technological changes, which are emerging along with it, areas of reliability and safety are going to face some additional challenges. The overall system's reliability may be improved with multi source heterogeneous data, such as multi source sensors and intercommunication within the system. The 
fourth industrial revolution will bring the new solutions for predictive maintenance, scheduling and machining process optimization for energy saving [19].

\subsection{Cloud computing}

Information technologies are able to provide the solutions for the challenges that are occurring in the manufacturing industry. Industry 4.0 and cloud manufacturing are two main concepts for the manufacturing that have been proposed in designing the new business paradigm. Cloud computing refers to a new paradigm related to a group of machines connected in a system in order to provide high-level service, with the use of Internet [20]. It is necessary to meet customization of manufacturing demands on a timely basis in the Fourth Industrial revolution. That is why mobile services in cooperation with cloud computing having been introduced [21]. Because of their high capacity and speed, cloud computing has adopted flash memory as the main storage, to achieve more efficiency [22].

\subsection{Application in today's industries}

With the advances in new-generation information technologies, especially big data and digital twin, smart manufacturing is becoming the focus of global manufacturing transformation and upgrading. Intelligence comes from data. Integrated analysis for the manufacturing big data is beneficial to all aspects of manufacturing [23]. The advancement of Industry 4.0 affected the medical sciences and health services, particularly in the field of big data research. Internet of Things and Cloud computing are believed to be one of the key contributors in the overall improvement of general health care.

However, it is still a great challenge to implement such technologies, but the number of articles on this subject witness the rise of the interest [24]. In industry 4.0, people, machines and products communicate with one another via the internet. Modern machines allow companies to exploit the potential of digitalization in their production facilities and to unlock new business fields.

Production processes and supply chains will become more efficient, with advances in productivity and huge savings in material and energy. Online platforms facilitate market access, reduce transaction costs and enable innovation through new business models. In Industry 4.0 context, the collection and comprehensive evaluation of data from many different sources will become standard to support decision making. Education should also follow new trends by providing programs, which are dealing with both mechanical engineering and IT, which is big change for conservative mechanical engineering since value chains are getting digitalized.

Such changes require creative workers with decision-making skills [25]. Industry 4.0 and the Internet of Things (IoT) revolution provide opportunities for developing effective industrial applications that efficiently tackle the triple-helix sustainability challenges associated with operations in industrial systems [26]. In the industry 4.0, artificial intelligence and machine learning will significantly make an impact on personal selling and sales management [27].

With the increase of competition in the airline industry, the structure of the industry has been modified. These changes have resulted in better efficiency and have caused the airlines to modify operational strategies. The sector has witness-growing virtualization [28].

Industry 4.0 is influencing the shipbuilding companies, creating the Shipyards 4.0. In this industry, the focus is on the optimizing the processes in an integrated network as well as the Augmented Reality, resulting in the Industrial Augmented Reality (IAR) [29].

\section{Education and qualification of people}

\subsection{Lack of educated workforce}

It is not possible to switch to Industry 4.0 over the night. There is obvious lack of qualified workers and financial costs are high. It brings new methodologies and technologies, which will have to be introduced into 
company. The emerging technologies have huge effect on the education of people. Only qualified and highly educated employees will be able to control these technologies. The industry should collaborate with universities. The companies should be focused on the development of qualified workforce by the Human Resources Management, which is not only focused on selection, staffing and dismissing employees but also on human resource development, i.e. education, learning and training of employees [30]. Developing countries are facing very hard problem. Education system is primarily theory based, so graduates need more training before they are employable.

The relevant stakeholders from Academia, Industry, Government, workforce, and multipliers will have to be brought together on a platform and their contributions and takeaways clearly defined to make New alliances with strategic partners from other countries will have to be forged [31]. In the manufacturing education and the workforce training, all of the innovative technologies of the Industry 4.0, will be included. As a result, a new educational paradigm will be created, a different kind of students will emerge from such system [32].

\subsection{University changes}

I order to facilitate learning and preparing employee for current challenges in industry, it is necessary to make some changes in universities itself. One example of this approach is Graz University, which has established Lean Lab, as a learning factory to enhance academic education, provide company trainings and hands-on research in the fields of industrial engineering and logistics with aim to enable practice-oriented learning in environment close to industrial reality [33]. A Learning factory is defined as an idealized replica of sections of the value chain industry where informal, non-formal and formal learning take place [34]. Training sessions for workers will be designed to prepare them for the Industry 4.0 environment in the factory of the future. These trainings will focus on the development of the skills and qualifications necessary for workers to cope with the increasing complexity in industrial environments [33]. During gradual changes, various job positions will disappear and some will be newly created [30].

Study programs in sectors other than just ICT must prepare students for it in an interdisciplinary way. Noninformatics students can be taught about Industry 4.0 using simulation games, and they are already used in logistics and production education in order to meet challenges of Industry 4.0. It became common method in schools and universities to prepare students working in "real life" situations. The advantage of learning in simulated environment is that the effect of decisions and actions can be experienced in a safe, fast and inexpensive environment; restart of the game is always possible [35].

Web 4.0 - a "read-write-execution-concurrency" web is most frequently shaping internet as a cloud, and encompassing both humans and machines in a creative interaction. The Web 4.0 goes well along with Industry 4.0, marked with cyber-physical systems, real-time responsiveness and cloud-based systems. Education evolved from relying completely on the teacher, as a sole source of knowledge, to expanding it toward the social networking, blogs, podcasts, communication and similar technologies. We are about to witness the new era of education, as a result of Web 4.0 and Industry 4.0 [36].

\subsection{Library 4.0}

The Library 4.0 is the concept of library associated with the era of Industry 4.0. Its concepts and model can be adapted to every kind of library. In the design of Library 4.0, major reference databases were examined. Furthermore, all of the new information technology advances and techniques were studied, so it is able to be applied in the design of a new age library. Library 4.0 is planned to be highly connected to Web 4.0, which is characterized with reading, writing, and executing simultaneously, intelligence-based agents, connected web, ubiquitous web, intelligence connections, and intelligence-based web.

The features of Library 4.0 are agreed to be: intelligence-based, massive data, augmented reality, context aware, cutting-edge displays, and infinite creative space. In the context of Web 4.0 and Industry 4.0, the main 
keywords to describe Library 4.0 are: Intelligent, Maker-space, Context-Aware Technology, Open Source, Big Data, Cloud Service, Augmented Reality, State-of-the-art Display, and Librarian 4.0 [37].

\section{Production and manufacturing in industry 4.0}

The development towards Industry 4.0 has presently a substantial influence on the manufacturing industry. It is based on the establishment of smart factories, smart products and smart services embedded in an internet of things and of services called industrial internet. This development towards an Industry 4.0 provides immense opportunities for realizing sustainable manufacturing using the ubiquitous information and communication technology (ICT) infrastructure. The allocation of resources, i.e. products, materials, energy and water, can be realized in a more efficient way on the basis of intelligent cross-linked value creation modules. Industry 4.0 holds a great opportunity for realizing sustainable industrial value creation on all three sustainability dimensions: economic, social and environmental, on micro and macro prospective. On macro prospective it has opportunities in evolving business models and value creation networks.

For the micro prospective opportunities are stored equipment, human, organization, process and product [38]. Germany is the first country to take initiative for computerization of manufacturing, which they called 'Industry 4.0'. Among others, there is also USA, with Smart Manufacturing Leadership Coalition, and Japan and Korea, with its own movements for smart manufacturing. The main characteristics of Industry 4.0 is introduction of IoT (internet of Things), and Internet of services into manufacturing, which allows creation of smart factories. These smart factories are characterized by devices with RFIDs, sensors and embedded systems, which collect data, analyze them and send either them somewhere else or take actions based on them. These systems are called cyber-physical systems (CPS) and their potentials from manufacturing and economic side are yet to be further explored and analyzed [39]. The fourth industrial revolution is characterized by the introduction of the Internet of things (IoT) and Internet of services concepts into manufacturing, which enables smart factories with vertically and horizontally integrated production systems. Variants are selfdetermined through items delivering their own production data to intelligent machines, which are aware of the environment, exchange information, and control processes in production and logistics by themselves. Data are collected along the entire life cycle in large quantities. In order to realize this vision, elements such as machines, storage systems, and utilities must be able to share information, as well as act and control each other autonomously. Such systems are called cyber-physical systems (CPS).

CPS can be seen as systems of systems, which require collaboration of different disciplines such as mechanical engineering, electrical engineering, and computer science for their realization [39]. Manufacturing companies face growing production requirements, which can be only handled by intelligent systems. During the last decades, the trend in manufacturing has shifted from the classic mass production to complex individualized products, which have to be produced to compete with the cost of mass products. In Germany, more than $50 \%$ of companies concern themselves as with topic Industry 4.0, but in general this value is just $10 \%$. Companies from US are ahead of the German and Japanese companies regarding investment and revenue in Industry 4.0. More than 50\% of companies have planned or already implemented Industry 4.0 applications. When talking about trends, physical assistant systems are used in a way that robots support the worker by holding or turning heavy parts.

Machine to machine communication means that machines are able to communicate with each other to improve the process flow, do capacity automatically planning and reduce the process time. Radio Frequency Identification (RFID) and Near Field Communication (NFC) are technologies, which makes it possible to send information by wireless. QR-codes are one of the most widely encountered codes and for industrial usage QRCodes can be used to identify parts or tools and that information can be automatically transferred to a database. QR-codes are also often used to provide customers with more information about a product. To the costs of mass production parts companies will be able to produce high-tech individualized parts according to customer's requirements [40]. European countries have been announcing their Industry 4.0 strategy, which is 
leading to the development of technology roadmaps and research agendas. It is expected from Industry 4.0 to have impact on five key areas: transport, energy, well-being, industry and infrastructure. Industry 4.0 aims at the purposeful collection and application of real time data and information by means of networking all individual elements, in order to reduce the complexity of operations, while increasing the efficiency and effectiveness with a long-term cost reduction target.

It is expected to influence following long-term paradigm shifts that are going to change European manufacturing: improvements in resource efficiency and sustainability of manufacturing systems, increased geographical proximity and acceptance, integration of customers in design and manufacturing processes, distributed and responsive manufacturing through collaborative processes, enabling mass customization of products and services and human-oriented interfaces and improved work conditions [91].

\subsection{Smart manufacturing and smart factory}

Intelligent manufacturing is one of the key roles in the Industry 4.0, where the resources are converted into smart objects, so they are able to act within a smart environment. Internet of Things, Cloud system and Cyberphysical systems are only some of the features of the intelligent manufacturing [41]. Modern world is moving its manufacturing process to cloud-based and distributed manufacturing. In this type of manufacturing, product is being produced near the place of consumption or use using Additive manufacturing, such as 3D printing. This helps reduce cost of transportation and logistics, and it makes additive manufacturing integral and promising technology of Industry 4.0. Based on extensive literature review, the biggest prospective in Additive manufacturing is in dental and medical industries, including organ and tissue fabrication, custom prosthetics etc. Other industry fields in manufacturing are adopting Additive Manufacturing and thus, disrupting traditional supply chains [92]. In the Fourth Industrial Revolution the information generated is automatically collected, transported and processed.

Cloud based systems along with computing and connectivity are the main concepts of this transformation. Smart manufacturing in terms of Industry 4.0 refers to a new paradigm characterized by the transition from disconnected machines to those that are interconnected via networks, data, and process models. The idea behind the Smart manufacturing is not new, but the ways of implementation are recently being discussed. With the integration of new IT technologies, new manufacturing processes have closed the gap between digital models and their physical counterparts [42]. Cyber-Physical Production System aims to integrate all the separate functionalities of a manufacturing environment into a single system. To apply the dynamical scheduling onto the environment of Industry 4.0, collaborative and distributes solution process is needed. CPPSs need to be designed so they can modify the schedules, and be flexible regarding it [43]. Flexibility has recently gained increasing attention. A persistent trend of globalization supports competitive pressure, while significant market fluctuations and increasing demands for individualized products prevail. One of the biggest challenges within these boundaries is sustainable competitiveness.

It is focused on various aspects of the topic such as definitions of manufacturing flexibility, dimensions, classifications and taxonomies, measurement of flexibility, the relationship between uncertainty, flexibility and performance, or the dimension of supply-chain flexibility which can be reactive and proactive [45]. Interoperability represents a characteristic where the components of a manufacturing system can exchange information between one another [46]. Smart manufacturing or Industry 4.0 are focused on integrating and connecting hardware, software and data to increase operational efficiency, asset availability, and quality while decreasing unscheduled downtime and scrap.

This translates into manufacturing operations becoming more efficient to keep up with changing consumer demand and increasing competition. Some governments have research focused in advancing the means of assessing, verifying and validating prognostic technologies operating within manufacturing environment [47]. Smart factory introduces flexible and reconfigurable production process. Its framework includes industrial 
network, cloud, supervisory control terminals, etc. High flexibility is possible to achieve due to autonomous decision and distributed cooperation between agents [48]. The current structure of digital factory needs to be transferred to smart factory via enabling communication between previously independent machines and systems. This transition includes emergence of cyber-physical systems (CPS). To allow this transition, many new technologies were waiting to appear, mainly, IoT, Big Data and Cloud computing. With transition from digital to smart, Overall Equipment Effectiveness (OEE) of the equipment is significantly improved. For actual communication, three layers are needed physical, network and application layer. In physical layer, all equipment needs to have means of receiving, processing and sending data. In network layer, new protocols and new standards have to be established. In application layer, means for semantic and high-level analysis of data must be enabled [49].

\subsection{Assembly system}

In the idea of "Smart manufacturing", there is also a term of "Smart factory", characterized with Big data, collected from many industrial processes. In addition, there is a Cyber-Physical System to monitor all the physical processes. Smart factory is also marked with connectivity of different production systems and resources. As a result, the assembly system is highly influenced by the Industry 4.0, even in the manual assembly, where human factor is prevailing [50].In order to maximize the system and production performances, the assembly system is used as a main management strategy. The assembly line needs to consider the industrial environment under which it operates, therefore the topic of assembly systems in Industry 4.0 is a popular topic. Industry 4.0 is consisted of technology that is characterized of the Internet connected devices, which made the digitalization of the assembly line possible [51]. Managing the production line in the model of customized mass production in food industry is one of the challenges that Industry 4.0 is handling. The goal is to produce different kinds of products without configuring the production line [52]. Although various demonstration systems of factory automation have been developed for manufacturing, most of them have many similarities on their main components and functions. Such systems can make the manufacturing system much more flexible and dynamically adjust the production task according to the plan and order. A consumer can release production order on the web according to user need; the production line will produce the specific kind of cars, such as the color and type of automobile. The first thing that should be done when developing ontology for the manufacturing domain is the common concept that is involved in all major portions of knowledge specification. We can obtain all the knowledge by consulting domain experts and referring to relevant knowledge base [53].

\subsection{Lean production}

Lean Production was invented by Toyota back in the 1950s, which is widely accepted in the industries in 1990s. It represents principles for controlling production sites, and describes the synchronized way that a production should be organized to achieve maximum productivity, focusing on value added activities, avoiding waste and minimizing the costs, while producing the highest quality products [44]. The Computer Integrated Manufacturing (CIM) era was short-lived, regardless of the good idea behind it, and due to the complexity of the required automation technology. A new paradigm we face today, called Industry 4.0, may relive the CIM, which is expected to have a better response in modern world, due to the better technology and general advancement that society have witnessed.

The Computer Integrated Manufacturing together with the Lean production may give rise to a new production system called Lean Automation and could be a new major cornerstone of Industry 4.0 [54]. Lean Production concerns the strict integration of humans in the manufacturing process, a continuous improvement and focus on value-adding activities by avoiding waste. Industry 4.0 has recently emerged in the manufacturing sector. It allows creating a smart network of machines, products, components, properties, individuals and ICT systems in the entire value chain to have an intelligent factory. Thus, the concept of Industry 4.0 can be perceived as a strategy for being competitive in the future. It is focused on the optimization of value chains due to 
autonomously controlled and dynamic production. It covers the design and implementation of competitive products and services, the administrative powerful and flexible logistics and production systems. In order to achieve the increased automation, the technological concepts of Cyber Physical Systems (CPS) can be used to work autonomously and interact with their production environment via microcontroller, actuators, sensors and a communication interface. Future trends and goals are to introduce and use Internet of Things, Cyber Physical System through Smart Factory by virtualization and integration [55]. Digital developments like cyber-physical Systems are the key technologies for future and more agile production system. To identify lean production supporting industry 4.0 technologies, the focus is on the technical perspectives of cyber-physical systems integrated into an industrial environment. The main key technology for industry 4.0 is cyber-physical systems (CPS) and its application is cyber-physical production system (CPPS). Industry 4.0 technologies based on CPPS elements can be grouped into data acquisition and data processing, machine-to-machine communication (M2M) and human-machine interaction (HMI). First combination of lean production and industry 4.0 was started in cooperation with a global automotive company. The highest impact of industry 4.0 on lean production is expected to be by machine-to-machine communication on kaizen, JIT, takt time and waste reduction, whereas human-machine interaction could have the best impact on standardization, manmachine separation, people and teamwork and kaizen.

Data acquisition and data processing through big data, analytics and cloud computing is expected to have the best impact on JIT, kaizen, standardization, and takt time [56]. Huge competition in a market gives customers high degree of freedom, so this increases the need of individual products ("mass customization"), whereby a constant cost and quality level is demanded. Processes and methods along the entire value chain have to be designed in a productive, efficient and flexible manner. Vertical and horizontal integration have major impact on processes form lean production, so implementation of horizontal and vertical networking by industry 4.0 enables a better integration of customers and suppliers into the (value-adding) process [57].

\subsection{Quality improvement}

The use of data-mining as an analytical tool has been increasing in recent years; and the emergence of new manufacturing paradigms such as the Industry 4.0 initiative have led many smaller manufacturers to look at utilizing these powerful techniques; however, practical applications are still in their infancy, and remain out of reach for many of these small manufacturing enterprises. Data mining can be used to explore the concept of Intelligent Manufacturing under Industry 4.0 in terms of improving product and process quality [93] [94] [95]. Techniques were developed using open-source and freely-available software, readily available hardware and only existing data-collection points in order to improve manufacturing operations [58]. The overall aim of the Industry 4.0 is to increase cost- and time-efficiency, and improve product quality, which requires a broad understanding of the enabling technologies as well as methods and tools. Many SMCs - which are small and medium-sized companies with less than 250 employees and a turnover less than 50 million/year - in Germany face difficulties concerning adaption and application of the necessary tools and technologies of Industry 4.0 due to knowledge and organizational barriers.

Therefore, there is an increasing need for supporting processes and models. The introduction of an Industry 4.0 based quality control necessitates integration steps within and outside the manufacturing company. It affects sensor and actuators as well as general company processes, like information and documentation flows. Furthermore, company partners or customers must be integrated into the development as they are all part of the overall value chain [59]. Electronic tools are a new direction in ergonomics. With the support of mobile applications, we see a way to create healthy conditions at work for production and also non-production workers, assembly and logistics. Traditional knowledge and modern technologies are combined into solutions for elimination of the risk at the workplace. The results are innovative and advanced ergonomic tools based on Industry 4.0 concept [60]. 


\subsection{Implementation}

One of the main characteristics of Industry 4.0 is support the integration and virtualization of manufacturing design and production process using the information and internet to create smart products. The Industry 4.0 concepts involve the integration of the physical and digital technologies with the phases of the Product. When this integration happens, the company can allocate efficiently the machines, identify problems quickly, reduce the production bottleneck, optimize process, reduce defects in products and prevent problems before manufacturing the prototype. All this together reduce product development time and provide customization to the production. Some other objectives of Industry 4.0 are to have better interaction between Human Machine Interface, to track and self-recognize parts and products through intelligent machines, to optimize production based on the communication of the IoT, etc [61].

For every implemented system in manufacturing process, there is some type of architecture. Supervisory control-based navigation architecture is a new architecture suitable for mobile robot navigation in warehouses and smart factories. This architecture embraces decentralization in which modular controller is embedded in mobile robot and planner runs externally. Without any major modifications of factory environment, this architecture is adaptable to changes in production line. Major advantage is a modularity of architecture, which allows increased adaptability [62].

The new concept and propose an architecture that is an open and distributed product/service production arrangement, called PSA (Product/service architecture) relying on a cloud system of systems. This architecture could generate different manufacturing arrangements including several adaptations mean to fit target product/service, not yet addressed by CPS manufacturing arrangement proposals. PSA proposes a distributed architecture to product/service production arrangement based on a cloud system of systems. For these characteristics, this architecture could be a formal base to generate different manufacturing arrangements including several adaptations meant to fit a target product/service [63]. Cloud computing and social media have been made to cover all of the necessary aspects of the total customer's experience. In addition, the Cyber-Physical System (CPS) technologies are designed to change in real time according to the customer's needs. In this way, the Smart manufacturing, which was enabled by Industry 4.0, is changing the entire production cycle, making specific products more profitable for the industries [64].

With the Industry 4.0, more flexible and efficient production can be reached, and with the modelling of the production systems, all of the delays and interrupts could be treated on time. Therefore, the experts must invest in a concept of a flexible production system, which has evolved from craft production to today's fourth industrial revolution's smart production [65].With the emergence of Industry 4.0, another concept was born: Logistics 4.0. This modern-day logistics are concerned about adequate requirements and enabling organizations to be efficient and fully operational.

Logistics 4.0 is not intended to replace humans in their fields, but to reduce inaccuracies and have faster processes, which are all mandatory with the emerging technologies of Industry 4.0 [66]. A very recent and important trend is to combine and connect production systems in industry with the "internet of services and things" in order to achieve a highly flexible and efficient production. In order to receive realistic results, the modeling methods should be able to consider the special characteristics of production systems in industry 4.0. The existing conventional modeling methods such as Markov Models and Petri nets can be used to model production processes and repairable systems. The evaluation shows that Petri nets have unique advantages and are more suitable than other methods to simulate the production systems in industry 4.0. Petri nets were used as a graphical modeling formalism for state-discrete systems [67]. 


\section{Industry 4.0 in business and management}

Industry 4.0 would not be able to emerge if it was not for the digital advancement that paved the way. The business transformation presented in the many reference models, is required in order to make traditional manufacturing process evolve into the smart manufacturing Industry 4.0 process style.

These models are mainly technological aspects of the implementation of smart systems, and they are not concerned with the business transformation, which is necessary to make the vision of smart manufacturing alive [69]. To make firms getting closer to the industry 4.0 phenomenon key concepts have been suggested suc as: service orientation, networked ecosystems and customer orientation. Furthermore, the impacts on the creation, delivery, and capture of value through the reconfiguration of Business Models due to embracing the Industry 4.0 are depicted [70].

\subsection{Supply chain management}

Industry 4.0 emphasizes communication and networking between tools and devices by openly exchanging information and controlling each other. Thus, collaboration between suppliers, manufacturers and consumers in supply chain is crucial for transparency from the beginning to the end. With the emergence of connectivity between machines comes endless set of possibilities in cyber-physical context and thus, changes in traditional structure of supply chain are inevitable. T

his disruption in supply chain management (SCM) could be seen through four different functions in a supply chain: procurement, transport logistics, warehouse and order fulfillment [71]. Innovative solutions in both technology and organization can be implemented by logistics, which in the era of globalization play a very important role. This applies not only to functioning of individual companies, but also to national economies and even the world economy. Big data allows us to quickly and efficiently manage and use this constantly growing database on more advanced way, since traditional tools are not enough and are slow to process all data, we have. Industry 4.0 is a consequence of IoT and Big Data and it brought us intelligent (smart) products, 3D printers or autonomous vehicles. It is assumed that intelligent factories will largely have the ability to self-plan and self-adapt. The newest solutions such as Internet of Things, Big Data and Industry 4.0 create opportunities to meet the needs of customers (requirements related to lead time delivery services, product availability and reliability) and also contribute to the development of logistics and supply chains management [96].

\subsection{Maintenance planning}

Cyber-Physical Systems (CPS) and Industrial Internet of Things (IIoT) rely on the combination of sensors and computing infrastructure. In the future, all of the fields of environment will be connected to some sort of smart system. To reduce the unplanned downtime and to improve the product quality, the maintenance planning and quality assurance emerged as one of the main decision-making activities [72]. Opportunities for sustainable offerings exist by designing products for longevity, repair and recycling, such that sustainability is not only focusing on being more efficient, but also on using less raw materials and recycling more products. Industry 4.0 can be used to help in creating sustainable business model. The strategy for the supply chain is clear: The most straightforward way to reduce the need for new raw materials and make them recoverable is through offering a durable product that is designed for "recyclability, disassembly, maintainability, refurbishability, and reusability". What changes under Industry 4.0 is that products "know the parameters within which they can function optimally and are able to recognize signs of wear and tear throughout their life cycle". To enable high-tech competitive advantage, Industry 4.0 has been introduced. It could be an enabler to sustainable business models, but it can also be an inhibiter by further exploiting the possibilities of neo-classical business models [73]. 


\subsection{Data management}

One of the most important factors in Industry 4.0 environment is data management, big data management to be correct. It is done with use of cyber-physical systems (CPS), internet of things (IoT) and cloud computing. Workers have to learn to deal with new situation and accept the term of life-learning process, constantly improving their performance. Since products have so far been used in term of "smart products" to include information about customer's customization demands and use feedback, the idea is to spread the use of data "smart product" collects for a use in automatized knowledge databases so the three main phases between product's design and development and manufacturing process. Those are process planning; operation sequencing and scheduling and they should be automatized and the knowledge of it should be imported in a system that could plan the process and do the scheduling based on the CAD and CAM model of future product and order from the customer as well. This is the new role and environment of a process planner in the Industry 4.0 that should be achieved. CAPP (computer aided process planning) is part of CIM and it means implementation of artificial intelligence in process planning [74].

This new industrial paradigm brings together the digital and physical worlds together through the CyberPhysical Systems enhanced by Internet of Things and it is expected that this novel has consequences on industry, markets and economy, improving production process and increasing productivity, affecting whole product lifecycle, creating new business models, changing the work environment and restructuring the labor market [75].

\section{Challenges}

In Germany called Industrie 4.0 and in North America Industrial Internet, both names represent the same concept of the upcoming industrial revolution. However, even though the governments started to fund the modern research efforts, many people ask themselves "Is it a hit or hype?". Many agree that it is still something that is waiting in the future, but is also inevitable. If the fourth industrial revolution successfully overcomes the challenges it may face in the future, it is certainly a big hit [77]. In the fields of Production and Operations Management, the researchers and practitioners are facing new challenges, namely, the Sustainable Development Goals and the Industry 4.0. Sustainable Development Goals are agenda created by United Nations that tackle the sustainable environment issues for the future world. The Industry 4.0, or the Fourth Industrial Revolution, represents a challenge due to a new approach to production and general organization in the manufacturing [76].

The advancement of manufacturing in the Industry 4.0 made the entire concept also referred to as "smart manufacturing", "industrial internet" and "integrated industry". However, the complete definition of the concept lacks clear understanding and is not fully established in the practice yet. That is why many professionals have presented certain scenarios and potential implications of this phenomenon. This change in the industry was necessary to be born, in order to meet the future production requirements [78].

\subsection{Risk in industry 4.0}

Industry 4.0 started as a philosophical concept in Germany and today became a highly researched and anticipated era. Risk in the Fourth Industrial Revolution lies upon the fact that the Industry will highly rely on the networking, integration of safety, security strategies and development of standards. Cyber security is concerned about the possible attacks on the operational technology, which would lead to multi-million damages. Since new age control systems are based upon constant communication and connectedness, the risk is even higher for the possible attacks on the security. Furthermore, research shows that there is an increase in the number of reported industrial control system incidents, and significant amount of the incidents emerged due to the lack of good industrial control network architecture [79]. The early implementations of the Industry 4.0 have concluded that the network between humans, systems and objects has become more complex and dynamic. Moreover, the upcoming fourth industry is marked with many new approaches and frameworks, 
along with more complex infrastructure. That is why, in the field of risk management, all of these new risks may occur [80].

\subsection{Standardization}

In recent times, society started to be aware of its footprint on the environment and with the emergence of the Industry 4.0 emerges a need for synthesis of these new 'de facto' standards with environmentally sustainable manufacturing. Proposal for more efficient synergy of these two movements is made through eleven distinct socio-economic moves for every manufacturing entity. These guidelines include the adjustments of following parts/roles of an organization: Management leadership, Organizational change readiness, Top management commitment, Strategic alignment, Training and capacity building, Empowerment, Teamwork and team implementation, Organizational culture, Communication, Project management and National culture and regional differences. In order to achieve maximum efficiency each manufacturing entity should follow these guidelines [81]. Many automation technology providers worldwide, and especially in Germany, have recognized the potentials of the Fourth Industrial revolution. However, many models so far have isolated production systems. So, to make Industry 4.0 successful, solutions must be open and standardized [82].

\subsection{Technological challenges}

The Internet of Things, Big Data, Cyber Physical Systems, Machine Learning, Additive Manufacturing, Robotics, and many other similar concepts are the phenomena and concepts associated with Industry 4.0. Integrating these technologies in order to improve the efficiency and responsiveness of the production system is the main idea behind the Industry 4.0. The power of this new wave of technological inquiry still waits for the improvement in integration and coordination of each of the technologies that are associated with Industry 4.0 [83]. The degree of technological complexity increases with the Industry 4.0. Beside the technological innovation, the manufacturing tasks in human and Cyber Physical Systems interaction changes. In both the design and operating phase, the engineers and manufacturers need to handle the increased complexity. In the quality and maintenance engineering, the operators need to keep the production system running [84].

Future's energy system, in the context of Industry 4.0, lies in the community energy system planning (CESP). High energy consumption resulted in problems related to energy supply. The main issue is how to get enough of the renewable and sustainable energy, which is going to be cost-effective, and on the other side, to improve the energy efficiency and energy demand management. There is a high pressure on the industry energy system with the rise of Industry 4.0. Its vision of all the production and industry machinery is integrated in CyberPhysical systems; smart factories distributed in different places; smart production system and model which improves the design and production; smart machines in the assembly line completely digitized and autonomously exchanging information [85]. In the last few years, the global economy and market requirements have been changing rapidly. The increasing demand for high complexity and the last technological developments potentiated by industrial transformation have led to the development of more complex and smarter products with new capabilities. Disruptive changes addressed by Industry 4.0 had impact in the whole product lifecycle, with the emergence of advanced digital tools for product development and prototyping that comprise advanced computing platforms, such as virtual and augmented reality. Allowing the combination of digital and physical prototyping, these technologies are rewriting the rules of product development processes, bringing new opportunities and challenges for SPD [86].

\subsection{Challenges in manufacturing}

Today's manufacturing enterprise must produce complex products that require high degree of specialization, and, at the same time, products must be personalized requiring flexible and agile response to meet the needs of modern customers (a very specific requirement and a wide range of needs). Traditional Flexible Manufacturing Systems are not able to fulfil requirements such as product personalization and to be economical in the same time, so there is need of new manufacturing systems - Reconfigurable Manufacturing 
System. An Innovative Production Network is a temporary alliance of enterprises that come together to share skills or core competencies and resources in order to better respond to business opportunities, and whose cooperation is supported by computer network.

Key goal of successful management of Production Networks is optimal partner selection and to achieve it, an evaluation of Virtual Enterprises must be made [87]. With the paradigm of Industry 4.0, the production faces new kinds of challenges and will need to adapt to the current market demand and solve many problems that arise. Customer rights are on a high priority of government policies, and consumers today require nonexpensive, high quality products coming to their doorstep. The supply chain management has not yet been dealt with high enough practice in the Industry 4.0. However, all of the terms and concepts associated with Industry 4.0, such as big data, Internet of Things, Cloud computing can maintain the competitive advantage in the long run, when combined with autonomous vehicles. As a result, the cost of the whole logistic network is decreased and emission level of $\mathrm{CO} 2$ is also decreased [88]. Industry of multiple supply chains has transformed into the circular model, by using the industrial and urban symbiosis.

Corporates believe that social, environmental and economic perspectives are highly appreciated in the crossindustry networks. However, there is a gap in the operational data-driven and recycle, reduce and reuse optimization solutions [89]. To meet challenges due to recent environmental, societal, economic and technological developments, manufacturing companies of the future will need capabilities for managing their whole value-chain in an agile and responsive manner. Companies will need virtual and physical structures that allow for close cooperation and rapid adaption along the whole lifecycle from innovation to production and distribution. Advances can also be seen on the organizational-economic level, e.g. Lean Management, on the manufacturing technology level, e.g. Laser technology, additive manufacturing [68], robotics on the material level, e.g. semi-conductors, nano-materials, carbon fibers, thin-films, biomaterials, on the information technology level, e.g. RFID, embedded systems. The maturity model is not intended as an easy route towards attaining Industry 4.0 maturity [90].

\section{Conclusion}

Industry 4.0 is not something that is comming and can be implemented over the night. It constantly brings new things and innovations in order to be more productive and efficient i production processes. Such phenomenon brings many benefits for today's production and ease many jobs in many ways. It prvides faster communication between people and machines, better and more precise analysis of data, provides access to many people in the same time to control various paramenters, bases etc.

All this require many adjustments to implement Industry 4.0 in its full capacity and to take as much benefits as possible. It brings competitive advantage to companies which handle better and faster with Industry 4.0 in a way to cut costs and waste, and to increase production capacities and to have better predictions for demand to not produce more than it is necessary. In order to be able to implement Industry 4.0 it requires better educated workforce and prepared students for real life environment and challenges that they are going to be faced with in order to be able to handle with new approach and to take as much benefits as possible.

So, government, universities and other related institutions have to take part in ease of implementation of Industry 4.0 and its popularity in business world. Such paradigm requires many sides to be included in order to smoothly implement this boon in every industry.

\section{References}

[1] "Australian Government/Department for Industry," [Online]. Available: https://industry.gov.au/industry/Industry-4-0/Pages/default.aspx. [Accessed 24 June 2018]. 
[2] S. Vaidya, P. Ambad and S. Bhosle, "Industry 4.0 - A Glimpse," Procedia Manufacturing, vol. 20, no. 3, pp. 233-238, 2018.

[3] H. Kagermann, "Change Through Digitalization - Value creation in the age of Industry 4.0," Management of Permanent Change, vol. 2, no. 3, pp. 23-45, 2014.

[4] D. Wang, "Building Value in a World of Technological Change: Data Analytics and Industry 4.0," IEEE Engineering Management Review, vol. 46, no. 1, pp. 32-33, 2018.

[5] F. Ansari, S. Erol and W. Sihn, "Rethinking Human-Machine Learning in Industry 4.0: How Does the Paradigm Shift Treat the Role of Human Learning?," Procedia Manufacturing, vol. 23, no. 10, pp. 117-122, 2018.

[6] T. Pereira, L. Barreto and A. Amaral, "Network and Information Security Challenges within Industry 4.0 Paradigm," Procedia Manufacturing, vol. 13, no. 9, pp. 1253-1260, 2017.

[7] M. Wollschlaeger, S. Thilo and J. Juergen, "The Future of Industrial Communication: Automation Networks in the Era of the Internet of Things and Industry 4.0.," IEEE Industrial Electronics Magazine, vol. 11, no. 1, pp. 17-27, 2017.

[8] A. Osseiran, O. Elloumi, J. Song and J. F. Monserrat, "Internet of Things," IEEE Communications Standards Magazine, vol. 1, no. 2, p. 84, 2017.

[9] V. Roblek, M. Mesko and A. Krapez, "A Complex View of Industry 4.0," SAGE Open, vol. 6, no. 2, pp. 1-11, 2016.

[10] P. Robison, M. Sengupta and D. Rauch, "Intelligent Energy Industrial Systems 4.0," IT Professional , vol. 17, no. 3, pp. 17-24, 2015.

[11] J. Wan, T. Shenglong, S. Zhaogang, D. Li, W. Shiyong, I. Muhammad and V. Athanasios, "Software-Defined Industrial Internet of Things in the Context of Industry 4.0.," IEEE Sensors Journal, vol. 16, no. 20, pp. 7373-7380, 2016.

[12] O. Yamila M., M. Minoufekr and P. Plapper, "Lessons from Social Network Analysis to Industry 4.0.," Manufacturing Letters, vol. 12, no. 7, pp. 8-12, 2017.

[13] R. Jose and S. Ramakrishna, "Materials 4.0: Materials Big Data Enabled Materials Discovery," Applied Materials Today, vol. 10, no. 1, pp. 127-132, 2018.

[14] B. Sun, S.-L. Jämsä-Jounela, Y. Todorov, L. E. Olivier and I. K. Craig, "Perspective for Equipment Automation in Process Industries," IFAC-PapersOnLine, vol. 50, no. 2, pp. 65-70, 2017.

[15] B. Bagheri, S. Yang, H.-A. Kao and J. Lee, "Cyber-physical Systems Architecture for Self-Aware Machines in Industry 4.0 Environment," IFAC-PapersOnLine, vol. 48, no. 9, pp. 1622-1627, 2015.

[16] E. Marilungo, A. Papetti, M. Germani and M. Peruzzini, "From PSS to CPS Design: A Real Industrial Use Case Toward Industry 4.0," Procedia CIRP, vol. 64, pp. 357-362, 2017.

[17] A. W. Colombo, S. Karnouskos, O. Kaynak, Y. Shi and S. Yin, "Industrial Cyberphysical Systems: A Backbone of the Fourth Industrial Revolution," IEEE Industrial Electronics Magazine, vol. 11, no. 1, pp. 6-16, 2017.

[18] M. Krugh and L. Mears, "A Complementary Cyber-Human Systems Framework for Industry 4.0 Cyber-Physical Systems," Manufacturing Letters, vol. 15, no. 1, pp. 89-92, 2018.

[19] Y. Jihong, Y. Meng, L. Lu and L. Li, "Industrial Big Data in an Industry 4.0 Environment: Challenges, Schemes, and Applications for Predictive Maintenance," IEEE Access, vol. 5, no. 2, pp. 23484-23491, 2017.

[20] Y. Liu and X. Xu, "Industry 4.0 and Cloud Manufacturing: A Comparative Analysis," Journal of Manufacturing Science and Technology, vol. 139, no. 3, pp. 1-8, 2016. 
[21] J. Wan, M. Yi, L. Di, Z. Chunhua, W. Shiyong and Z. Keliang, "Mobile Services for Customization Manufacturing Systems: An Example of Industry 4.0.," IEEE Access, vol. 4, no. 10, pp. 8977-8986, 2016.

[22] H. Jianfan, G. Jia, G. Han, H. Wang and X. Yang, "Locality-Aware Replacement Algorithm in Flash Memory to Optimize Cloud Computing for Smart Factory of Industry 4.0.," IEEE Access, vol. 5, no. 3, pp. 16252-16262, 2017.

[23] Q. QI and F. TAO, "Digital Twin and Big Data Towards Smart Manufacturing and Industry 4.0: 360 Degree Comparison," IEEE Access, vol. 6, pp. 3585 - 3593, 2018.

[24] M. Elhoseny, A. Abdelaziz, A. S. Salama, A. Riad, K. Muhammad and A. K. Sangaiah, "A Hybrid Model of Internet of Things and Cloud Computing to Manage Big Data in Health Services Applications," Future Generation Computer Systems, vol. 3, no. 1, 2018.

[25] S. S. F. -Mirandaa, M. Marcosb, M. E. Peraltaa and F. Aguayoa, "The challenge of integrating Industry 4.0 in the degree of Mechanical Engineering," Procedia Manufacturing, vol. 13, pp. 12291236, 2017.

[26] D. Bechtsis, N. Tsolakis, M. Vouzas and D. Vlachos, "Industry 4.0: Sustainable Material Handling Processes in Industrial Environments," in Computer Aided Chemical Engineering 27th European Symposium on Computer Aided Process Engineering, Barcelona, 2017.

[27] N. Syam and A. Sharma, "Waiting for a Sales Renaissance in the Fourth Industrial Revolution: Machine Learning and Artificial Intelligence in Sales Research and Practice," Industrial Marketing Management, vol. 69, no. 2, pp. 135-146, 2018.

[28] M. Castiglioni, Á. Gallego and J. L. Galán, "The Virtualization of the Airline Industry: A Strategic Process," Journal of Air Transport Management, vol. 67, no. 12, pp. 134-145, 2018.

[29] P. Fraga-Lamas, T. Fernandez-Carames and O. Blanco-Novoa, "A Review on Industrial Augmented Reality Systems for the Industry 4.0 Shipyard," IEEE Access, vol. 6, no. 10, pp. 13358-13375, 2018.

[30] A. Benešováa and J. Tupa, "Requirements for Education and Qualification of People in Industry 4.0," Procedia Manufacturing, vol. 11, pp. 2195-2202, 2017.

[31] A. Iyer, "Moving from Industry 2.0 to Industry 4.0: A case study from India on leapfrogging in smart manufacturing," Procedia Manufacturing, vol. 21, pp. 663-670, 2018.

[32] D. Mourtzis, E. Vlachou, G. Dimitrakopoulos and V. Zogopoulos, "Cyber- Physical Systems and Education 4.0 -The Teaching Factory 4.0 Concept," Procedia Manufacturing, vol. 23, no. 5, pp. 129$134,2018$.

[33] H. K. M. Hammer, M. Kleindienst and C. Ramsauer, "Transition towards an Industry 4.0 State of the LeanLab at Graz University of Technology," Procedia Manufacturing, vol. 9, pp. 206-213, 2017.

[34] F. Baena, A. Guarin, J. Mora, J. Sauza and S. Retat, "Learning Factory: The Path to Industry 4.0," Procedia Manufacturing, vol. 9, pp. 73-80, 2017.

[35] M. Zarte and A. Pechmann, "Concept for introducing the vision of industry 4.0 in a simulation game for non-IT students," Industrial Informatics (INDIN), 2017.

[36] D. Claudio and L. Benussi, "Do Web 4.0 and Industry 4.0 Imply Education X.0?," IT Professional, vol. 19, no. 3, pp. 4-7, 2017.

[37] Y. Noh, "Imagining Library 4.0: Creating a Model for Future Libraries," The Journal of Academic Librarianship, vol. 47, no. 6, pp. 786-797, 2015.

[38] T. Stock and G. Seligerab, "Opportunities of Sustainable Manufacturing in Industry 4.0," Procedia CIRP, vol. 40, pp. 536-541, 2016.

[39] K.-D. Thoben, S. Wiesner and T. Wuest, "'Industrie 4.0" and Smart Manufacturing - A Review of 
Research Issues and Application Examples," International Journal of Automotive Technologies, vol. 11, no. 1, pp. 1-13, 2017.

[40] M. W. Waibela, G. A. Oosthuizena and D. W. du Toita, "Investigating current smart production innovations in the machine building industry on sustainability aspects," Procedia Manufacturing, vol. 21, pp. 774-781, 2018.

[41] R. Y. Zhong, X. Xu, E. Klotz and S. T. Newman, "Intelligent Manufacturing in the Context of Industry 4.0: A Review," Engineering, vol. 3, no. 5, pp. 616-630, 2017.

[42] T. Kurfess and H. Ahuett-Garza, "Editorial: Foreword Industry 4.0 and Smart Manufacturing," Manufacturing Letters, vol. 15, no. 1, p. 59, 2018.

[43] D. Rossit and F. Tohmé, "Scheduling Research Contributions to Smart Manufacturing," Manufacturing Letters, vol. 15, no. 1, pp. 111-114, 2018.

[44] B. Durakovic, R. Demir, K. Abat and C. Emek, "Lean Manufacturing: Trends and Implementation Issues," Periodicals of Engineering and Natural Sciences, vol. 6, no. 1, pp. 130-143, 2018.

[45] M. Brettel, M. Klein and N. Friederichsen, "The Relevance of Manufacturing Flexibility in the Context of Industrie 4.0," Procedia CIRP, vol. 41, pp. 105-110, 2016.

[46] Y. Liao, L. F. P. Ramos, M. Saturno, F. Deschamps, E. Loures and A. L. Szejka, "The Role of Interoperability in The Fourth Industrial Revolution Era," IFAC-PapersOnLine, vol. 50, no. 1, pp. 12434-12439, 2017.

[47] B. A. Weiss, M. Helu, G. Vogl and G. Qiao, "Use Case Development to Advance Monitoring, Diagnostics, and Prognostics in Manufacturing Operations," IFAC-PapersOnLine, vol. 49, no. 31, pp. 13-18, 2016.

[48] S. Wang, J. Wan, D. Zhang, D. Li and C. Zhang, "Towards Smart Factory for Industry 4.0: A Selforganized Multi-agent System with Big Data Based Feedback and Coordination," Computer Networks, vol. 101, no. 6, pp. 158-168, 2016.

[49] B. Chen, J. Wan, L. Shu, P. Li, M. Mukherjee and B. Yin, "Smart Factory of Industry 4.0: Key Technologies, Application Case, and Challenges," IEEE Access, vol. 6, no. 1, pp. 6505-6519, 2018.

[50] Y. Cohen, M. Faccio, F. G. Galizia, C. Mora and F. Pilati, "Assembly System Configuration through Industry 4.0 Principles: The Expected Change in the Actual Paradigms," IFAC-PapersOnLine, vol. 50, no. 1, pp. 14958-14963, 2017.

[51] M. Bortolini, E. Ferrari, M. Gamberi, F. Pilati and M. Faccio, "Assembly System Design in the Industry 4.0 Era: A General Framework," IFAC-PapersOnLine, vol. 1, no. 2, pp. 5700-5705, 2017.

[52] J. Simon, M. Trojanova, J. Zbihlej and J. Sarosi, "Mass Customization Model in Food Industry Using Industry 4.0 Standard with Fuzzy-based Multi-criteria Decision Making Methodology," Advances in Mechanical Engineering, vol. 10, no. 3, pp. 1-10, 2018.

[53] H. Cheng, P. Zeng, L. Xue, Z. Shi, P. Wang and H. Yu, "Manufacturing Ontology Development Based on Industry 4.0 Demonstration Production Line," IEEE, 2016.

[54] D. Kolberg and D. Zühlke, "Lean Automation Enabled by Industry 4.0 Technologies," IFACPapersOnLine, vol. 48, no. 3, pp. 1870-1875, 2015.

[55] B. Mrugalska and M. K.Wyrwicka, "Towards Lean Production in Industry 4.0," Procedia Engineering, vol. 182, pp. 466-473, 2017.

[56] T. Wagner, C. Herrmann and S. Thiede, "Industry 4.0 Impacts on Lean Production Systems," Procedia CIRP, vol. 63, pp. 125-131, 2017.

[57] U. Dombrowski, T. Richter and P. Krenkel, "Interdependencies of Industrie 4.0 \& Lean Production Systems: A Use Cases Analysis," Procedia Manufacturing, vol. 11, pp. 1061-1068, 2017. 
[58] H. Oliff and Y. Liu, "Towards Industry 4.0 Utilizing Data-Mining Techniques: A Case Study on Quality Improvement," Procedia CIRP, vol. 63, pp. 167-172, 2017.

[59] V. Butenko, T. Stürmlinger, A. Albers, B. Gladysz and T. Pinner, "Procedure for Defining the System of Objectives in the Initial Phase of an Industry 4.0 Project Focusing on Intelligent Quality Control Systems," Procedia CIRP, vol. 52, pp. 262-267, 2016.

[60] M. Gašová, M. Gašo and A. Štefánik, "Advanced Industrial Tools of Ergonomics Based on Industry 4.0 Concept," Procedia Engineering, vol. 192, pp. 219-224, 2017.

[61] K. Santos, E. Loures, F. Piechnicki and O. Can, "Opportunities Assessment of Product Development Process in Industry 4.0," Procedia Manufacturing, vol. 11, pp. 1358-1365, 2017.

[62] A. G. Gonzalez, M. V. Alves, G. S. Viana, L. K. Carvalho and J. C. Basilio, "Supervisory ControlBased Navigation Architecture: A New Framework for Autonomous Robots in Industry 4.0 Environments," IEEE Transactions on Industrial Informatics, vol. 14, no. 4, p. 1732-1743, 2018.

[63] D. . S. Diogode and J. R. Silva, "Product-Service Architecture (PSA): toward a Service Engineering perspective in Industry 4.0," IFAC-PapersOnLine, vol. 49, no. 31, pp. 91-96, 2016.

[64] G. Antonino, L. Carnevale, A. Celesti, M. Fazio and M. Villari, "A Cloud-Based System for Improving Retention Marketing Loyalty Programs in Industry 4.0: A Study on Big Data Storage Implications," IEEE Access, vol. 6, no. 3, pp. 5485-5492, 2018.

[65] F. Long, P. Zeiler and B. Bertsche, "Realistic Modelling of Flexibility and Dependence in Production Systems in Industry 4.0 for Analysing Their Productivity and Availability," SAGE Open, vol. 232, no. 2, pp. 174-184, 2018.

[66] B. L., A. Amaral and T. Pereira, "Industry 4.0 Implications in Logistics: An Overview," Procedia Manufacturing, vol. 13, no. 6, pp. 1245-1252, 2017.

[67] F. P. and B.Bertsche, "Modelling the production systems in industry 4.0 and their availability with high-level Petri nets," IFAC-PapersOnLine, vol. 49, pp. 145-150, 2016.

[68] B. Durakovic, "Design for Additive Manufacturing: Benefits, Trends and Challenges," Periodicals of Engineering and Natural Sciences, vol. 6, no. 2, pp. 179-191 , 2018.

[69] C. Cimini, R. Pinto and S. Cavalieri, "The Business Transformation towards Smart Manufacturing: A Literature Overview about Reference Models and Research Agenda," IFAC-PapersOnLine, vol. 50, no. 1, pp. 14958-14957, 2017.

[70] D. Ibarra, G. Jaione and J. I. Igartua, "Business Model Innovation through Industry 4.0: A Review," Procedia Manufacturing, vol. 22, no. 12, pp. 4-10, 2018.

[71] T. B., C. Esplugues, E. Ares and G. Pelaez, "What Does Industry 4.0 Mean to Supply Chain?," Procedia Manufacturing, vol. 13, no. 6, pp. 1175-1182, 2017.

[72] K. Upasani, M. Bakshi, V. Pandhare and B. K. Lad, "Distributed Maintenance Planning in Manufacturing Industries," Computers \& Industrial Engineering , vol. 108, no. 6, pp. 1-14, 2017.

[73] J. C. de Man and J. O. Strandhagen, "An Industry 4.0 Research Agenda for Sustainable Business Models," Procedia CIRP, vol. 63, pp. 721-726, 2017.

[74] M. Trstenjak and P. Cosic, "Process Planning in Industry 4.0 Environment," Procedia Manufacturing, vol. 11, pp. 1744-1750, 2017.

[75] A. C. Pereira and F. Romero, "A review of the meanings and the implications of the Industry 4.0 concept," Procedia Manufacturing, vol. 13, pp. 1206-1214, 2017.

[76] L. E. Quezada, S. F. Chiu, S. E. Gouvea Da Costa and K. H. Tan, "Operational Excellence towards Sustainable Development Goals through Industry 4.0," International Journal of Production Economics, vol. 190, no. 8, pp. 1-2, 2017. 
[77] D. Rainer and A. Horch, "Industrie 4.0: Hit or Hype?," IEEE Industrial Electronics Magazine, vol. 8, no. 2, pp. 56-58, 2014.

[78] E. Hofmann and M. Rüsch, "Industry 4.0 and the Current Status as Well as Future Prospects on Logistics," Computers in Industry, vol. 89, no. 8, pp. 23-24, 2017.

[79] R. Piggin, "Risk in the Fourth Industrial Revolution," Itnow , vol. 58, no. 3, pp. 34-35, 2016.

[80] T. Jiri, J. Simota and F. Steiner, "Aspects of Risk Management Implementation for Industry 4.0.," Procedia Manufacturing, vol. 11, no. 3, pp. 1223-1230, 2017.

[81] A. B. Jabbour, C. Jabbour, F. Cyril and F. Moacir Godinho, "When Titans Meet - Can Industry 4.0 Revolutionise the Environmentally-sustainable Manufacturing Wave? The Role of Critical Success Factors.," Technological Forecasting and Social Change, vol. 2, no. 3, pp. 1-8, 2018.

[82] S. Weyer, M. Schmitt, M. Ohmer and D. Gorecky, "Towards Industry 4.0 - Standardization as the Crucial Challenge for Highly Modular, Multi-vendor Production Systems," IFAC-PapersOnLine, vol. 48, no. 3, pp. 579-584, 2015.

[83] H. Ahuett-Garza and T. Kurfess, "A Brief Discussion on the Trends of Habilitating Technologies for Industry 4.0 and Smart Manufacturing," Manufacturing Letters, vol. 2, no. 1, pp. 1-9, 2018.

[84] C. Wittenberg, "Human-CPS Interaction - Requirements and Human-machine Interaction Methods for the Industry 4.0," IFAC-PapersOnLine, vol. 49, no. 19, pp. 420-425, 2016.

[85] Z. Huang, H. Yu, Z. Peng and Y. Feng, "Planning Community Energy System in the Industry 4.0 Era: Achievements, Challenges and a Potential Solution," Renewable and Sustainable Energy Reviews, vol. 78, no. 10, pp. 710-721, 2017.

[86] M. N. Lopes, A. C. Pereira and A. C. Alves, "Smart products development approaches for Industry 4.0," Procedia Manufacturing, vol. 13, pp. 1215-1222, 2017.

[87] I. Veza, M. Mladineo and N. Gjeldum, "Managing Innovative Production Network of Smart Factories," IFAC-PapersOnLine, vol. 48, no. 3, pp. 555-560, 2015.

[88] V. Gružauskas, S. Baskutis and V. Navickas, "Minimizing the Trade-off between Sustainability and Cost Effective Performance by Using Autonomous Vehicles," Journal of Cleaner Production, vol. 184, no. 1, pp. 709-717, 2018.

[89] M.-L. Tseng, R. Tan and A. C. C.-F. K. T. C. Chiu, "Circular Economy Meets Industry 4.0: Can Big Data Drive Industrial Symbiosis?," Resources, Conservation and Recycling, vol. 131, no. 4, pp. 146$147,2018$.

[90] A. Schumacher, S. Erol and W. Sihn, "A Maturity Model for Assessing Industry 4.0 Readiness and Maturity of Manufacturing Enterprises," Procedia CIRP, vol. 52, pp. 161-166, 2016.

[91] C.Santosa, A.Mehrsaia, A.C.Barrosa, M.Araújob and E.Aresc, "Towards Industry 4.0: an overview of European strategic roadmaps," Procedia Manufacturing, vol. 13, pp. 972-979, 2017.

[92] E. Rauch, M. Unterhofer and P. Dallasega, "Industry Sector Analysis for the Application of Additive Manufacturing in Smart and Distributed Manufacturing Systems," Manufacturing Letters, vol. 15, no. 1, pp. 126-131, 2018.

[93] B. Durakovic and H. Basic, "Continuous Quality Improvement in Textile Processing by Statistical Process Control Tools: A Case Study of Medium-Sized Company," Periodicals of Engineering and Natural Sciences, vol. 1, no. 1, pp. 39-46, 2013.

[94] B. Durakovic and H. Bašić, "Textile Cutting Process Optimization Model Based On Six Sigma Methodology In a Medium-Sized Company," Journal of Trends in The Development of Machinery and Associated Technology, vol. 16, no. 1, pp. 107-110, 2012.

[95] B. Durakovic, "Design of Experiments Application, Concepts, Examples: State of the Art," 
Periodicals of Engineering and Natural Scinces, vol. 5, no. 3, p. 421-439, 2017.

[96] KrzysztofWitkowski, "Internet of Things, Big Data, Industry 4.0 - Innovative Solutions in Logistics and Supply Chains Management," Procedia Engineering, vol. 182, pp. 763-769, 2017. 